\title{
Effect of Rotary Friction Welding Parameters on the Mechanical Behavior ABS/PE Polymers
}

\author{
Gailan Ismail Hassan ${ }^{1}$, Younis Khalid Khdir ${ }^{2}$ \\ ${ }^{1}$ Erbil Technical Engineering College, Erbil Polytechnic University (EPU), Erbil, Kurdistan Region - Iraq \\ ${ }^{2}$ Erbil Technical Engineering College, Erbil Polytechnic University (EPU), Erbil, Kurdistan Region - Iraq
}

\section{ABSTRACT}

This study deals with the Rotary Friction Welding, (RFW) as a variation of friction welding in which the energy required to make the weld is supplied primarily by the stored rotational kinetic energy of the welding machine. The mechanical energy generated in overcoming friction is continuously transformed into heat. In most circumstances the thermal energy generated is regarded as undesirable, but under controlled conditions it can be used to join materials, as in the case of rotary friction welding. In this paper, similar and dissimilar joints of Acrylonitrile butadiene styrene (ABS) (chemical formula $\left.(\mathrm{C} 8 \mathrm{H} 8)_{\times} \cdot(\mathrm{C} 4 \mathrm{H} 6)_{\mathrm{y}} \cdot(\mathrm{C} 3 \mathrm{H} 3 \mathrm{~N})_{\mathrm{z}}\right)$ and Polyethylene $(\mathrm{PE})$ or polyethene or poly(methylene)) are studied. The effects of different rotational rates, plunge depths, and traverse speeds on the microstructure and tensile strength of joints were investigated. Some defects such as pores and cracks were found at inappropriate processing parameters. The tensile test was carried out as the mechanical properties of joints. Different significant parameters were discussed. The maximal and minimal tensile strength indicated and evaluated.

KEYWORDS : Friction welding, similar joint, dissimilar joints, High-density polyethylene.

\section{INTRODUCTION}

The joining of different polymers and plastic structures is a topic of high technological interest; knowing that the traditional joining techniques are usually not suitable for all applications, many researchers tried to provide new technics for welding plastic and polymer materials such acrylonitrile butadiene styrene (ABS) and polyethylene (PE) or polyethene or poly (methylene). The critical point about the effect of key processing parameters on the mechanical behaviour of the welding joints of ABS/PE show that there are some defects in the interface of the joint at a lower rotational speed and any increasing of rotational speed the number of defects decreased. Attention now is increasingly being given to the following research areas, both numerically and experimentally. Friction welding is a solid state process of joining of materials and structures below their melting points. When two materials come in contact with relative motion to each other, with the action of friction force, heat is produced

Academic Journal of Nawroz University

(AJNU) Volume 7, No 4 (2018).

Regular research paper : Published 21 December 2018

Corresponding author's e-mail : gailan_hareri@epu.edu.krd

Copyright (C2017 Gailan Ismail Hassan¹, Younis Khalid

Khdir ${ }^{2}$. This is an open access article distributed under the

Creative Commons Attribution License. and deformation takes place in the region of the contact face, due to this intermolecular and rising the temperature below their melting points, the diffusion is occurred between their faces and with upsetting pressure, then welding is performed. Normally friction welding concept originally done for similar material joining, but it was further applied for dissimilar materials (Singh, Kumar, Feo, \& Fraternali, 2016), (Kumar, Singh, Ahuja, Amendola, \& Penna, 2018). On this concept of friction welding was used for the similar materials like Copper Bars (Parsa, Davari, Hadian, \& Ahmadabadi, 2007). And for aluminum alloy (Aoki \& Koezawa, 2017). Some others used the similar welding technic for composite materials such as Ti-6Al-4V LFW (Bühr et al., 2018). And for joining polymers, friction welding used also, (Zafar, Awang, \& Khan, 2017). While widely welding of the dissimilar materials has been highlighted by many researches such as pure titanium and pure copper, (Kimura, Saitoh, Kusaka, Kaizu, \& Fuji, 2011), brass and low carbon steel, (Kimura, Kasuya, Kusaka, Kaizu, \& Fuji, 2009), AISI 304 with AISI 1021 steels, (Handa \& Chawla, 2014), friction welded joint of YSZ-alumina composite and 6061 aluminum alloy, (Uday, Fauzi, Zuhailawati, \& Ismail, 2011), 6061 aluminum alloy/YSZ-alumina composite, (Uday \& Ahmad-Fauzi, 2014). Silicon carbide and graphite particle reinforced AA6063 matrix hybrid composite, (Hynes, Prabhu, \& Nagaraj, 2017). The 
number of studies has been reported dissimilar welding between metals and plastic or polymer materials, joining of acrylonitrile butadiene styrene (ABS) and zinc-coated steel, (Jung, Cheon, \& Na, 2016), a case study on aluminum alloy AA6061 and MC Nylon-6, (Liu, Liao, \& Nakata, 2014), processes for joining of similar as well as dissimilar polymer/plastics and metal powder reinforcement for engineering applications presented in (Singh et al., 2016). Another challenge of dissimilar friction welding done by joining different types of polymers or thermoplastics, such as ABS and Nylon6, by (Singh et al., 2016), and friction welding between part of PMMA with PVC, (Lin, Wu, \& Chou, 2003), also dissimilar lap joints of high-density polyethylene (HDPE) and acrylonitrile butadiene styrene (ABS) sheets were prepared by (Gao, Li, Shilpakar, \& Shen, 2016). The mentioned papers deal with checking the mechanical, thermal and metallurgical properties of friction welded piece. But, there is a limitation of joining by rotary friction welded process of these thermoplastics that hinders its use in different engineering applications. Such as ABS and PE materials. In the present work attempts have been made to perform friction welding for dissimilar thermoplastic (ABS and PE) because of big differences between their mechanical properties, "ABS is tough and ductile with high stress and strength values, PE is soft and flexible, with low stress and high strength". In this research ABS is selected as the polymer material, because it is widely used in the industry due to its higher-level mechanical properties, ease of processing and recyclability and also it has a good chemical resistance. This variation is related to the big difference of their thermal conductivity for both ABS and PE polymer. Because poor thermal conductivity restricted the heat transfer between the two welded specimens. So in this study effort has been made to investigate the weld properties of rotary friction welded butt joints of ABS with PE, by controlling rotational speed and friction time in order to determine the tensile properties of the joints, because polymer materials are viscoelastic and their properties are dependent on time (Abdelbary, 2015). The effects of the process parameters such as rotational speed and exposed, at constant upset pressure were studied, The upset pressure is important parameter in controlling the friction welding process, and it is considered constant in this research. In the experimental procedure we explained preparing the ABS and PE rods, during rotary friction welding, average burning-off length, time before fracture, peak stress and joint efficiency are calculated, the fracture location showed, and the results explained in the next section, while the conclusion of the job was written in the last paragraph.

\section{EXPERIMENTAL}

\subsection{Materials}

In this research $27 \mathrm{~mm}$ in diameter of two different commercial polymer rods were used Acrylonitrile butadiene styrene (ABS) and Polyethylene (PE) or Poly Ethylene or poly (methylene). In tensile testing, the samples to be tested are machined to standard dimensions. Generally $6 \mathrm{~mm}$ round test specimen as shown in Fig. 1. Where, $G$ is gauge length $=32.0 \mathrm{~mm}, \mathrm{D}$ is diameter $=6 \mathrm{~mm}, \mathrm{R}$ is radius of fillet $=10 \mathrm{~mm}$ and $\mathrm{A}$ is length of reduced section $=50 \mathrm{~mm}$ according to the tensile machine standard. All specimens prepared for welding with $22 \mathrm{~mm}$ in diameter and $100 \mathrm{~mm}$ in length. The properties of the PE and ABS rods are presented in Table 1.

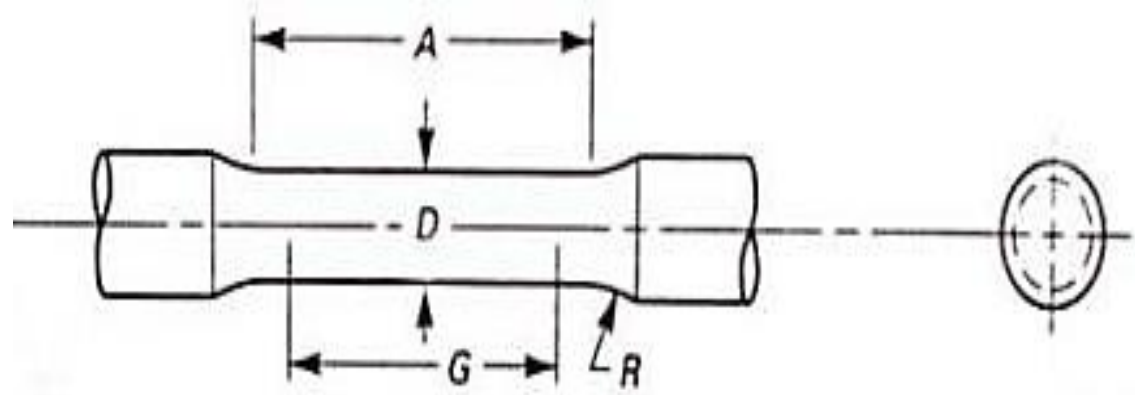

Fig (1) : Configuration of the specimen for tensile strength 
TABLE (1) : Properties of ABS and PE polymers according to ASTM standard

\begin{tabular}{|c|c|c|c|}
\hline & Properties & ABS & PE \\
\hline Physical & Density & $1.04-1.11 \mathrm{~g} / \mathrm{cm}^{3}$ & $0.935-0.945 \mathrm{~g} / \mathrm{cm}^{3}$ \\
\hline & Melt mass-flow rate & $1-36 \mathrm{~g} / 10 \mathrm{~min}$ & $0.04-5.4 \mathrm{~g} / 10 \mathrm{~min}$ \\
\hline Mechanical & Tensile strength, Yield & $34-51 \mathrm{MPa}$ & $13.78-21.1 \mathrm{MPa}$ \\
\hline & Elongation at break & $1-57 \%$ & $290-900 \%$ \\
\hline & Flexural Modulus & $1.53-2.87 \mathrm{GPa}$ & $0.474-0.854 \mathrm{GPa}$ \\
\hline & Flexural strength & $51.9-81.35 \mathrm{MPa}$ & - \\
\hline & Hardness, Rockwell & $91-115$ & $59-65$ \\
\hline & Load impact, notched & $2,46-2,94 \mathrm{~J} / \mathrm{cm}$ & No break \\
\hline & Maximum service temperature, air & $60-75^{\circ} \mathrm{C}$ & $<42{ }^{\circ} \mathrm{C}$ \\
\hline & Deflection temperature at $4,5 \mathrm{MPa}$ & $81-100{ }^{\circ} \mathrm{C}$ & $57-63{ }^{\circ} \mathrm{C}$ \\
\hline & Vicat softening temperature & $83-115^{\circ} \mathrm{C}$ & $114-126^{\circ} \mathrm{C}$ \\
\hline
\end{tabular}

The chemical formula of the ABS material is $\left(\mathrm{C}_{8} \mathrm{H}_{8} \bullet \mathrm{C}_{4} \mathrm{H}_{6} \bullet \mathrm{C}_{3} \mathrm{H}_{3} \mathrm{~N}\right)_{n}$. It is a common thermoplastic polymer, and it has no true melting point. ABS is a terpolymer made by polymerizing styrene and acrylonitrile in the presence of poly butadiene. For the many of the applications, $\mathrm{ABS}$ can be used for different range of temperatures, between $-20^{\circ} \mathrm{C}$ and $80^{\circ} \mathrm{C}$, and its mechanical properties depend on the temperature.
Polyethylene (PE) or Poly Ethylene or poly (methylene). Is the most common plastic. The chemical formula $\left(\mathrm{C}_{2} \mathrm{H}_{4}\right)_{\mathrm{n}}, \mathrm{PE}$ is a mixture of similar polymers of ethylene with different values of $n$. Table 2 show the results of the tensile test for two different polymer (ABS and PE) as received which indicated that they have same peak stress, which they have different fracture points and elongation.

TABLE (2) : Results of tensile testing of as received polymers

\begin{tabular}{|c|c|c|c|c|c|}
\hline $\begin{array}{c}\text { Polymer } \\
\text { type }\end{array}$ & $\begin{array}{c}\text { Peak stress } \\
\text { MPa }\end{array}$ & $\begin{array}{c}\text { Peak load } \\
\text { KN }\end{array}$ & $\begin{array}{c}\text { Elongation } \\
\%\end{array}$ & $\begin{array}{c}\text { Time } \\
\text { before } \\
\text { fracture sec }\end{array}$ & $\begin{array}{c}\text { Fracture } \\
\text { location }\end{array}$ \\
\hline PE & 29.9 & 0.843 & 0.013 & 7.92 & middle \\
\hline ABS & 28.38 & 0.801 & 0.038 & 4.14 & shoulder \\
\hline
\end{tabular}

\subsection{Procedure}

To do the fiction welding test we used the lathe machine in the workshop after choosing a suitable friction speeds from $650-1030 \mathrm{rpm}$, the first part of the sample was fixed well on the rotation clamp and other part was fixed on the tell stock, starting rotating the rotary chuck. By closing the two parts of the samples to each other till the friction welding occurred, in which the heat required to realize the weld is produced as a result of the rotary friction between two surfaces of the two parts rubbing against each other under controlled axial pressure. The rubbing of the two parts is continued until sufficient heat has been generated, till the mixed melted polymer material appears around the both parts, at this moment, the surface friction is stopped and the two pieces are welded together. This procedure repeated for other specimens with different rotating speed and the time varied between 60-105 seconds. These two friction variants, which controls the way energy is delivered to the system. After welding the total groups of the specimens which are arranged to three different groups by welding (PE with PE, ABS with ABS and PE with ABS), the entire welded specimen are cleaned from the additional melting materials using the lathe machine. Then the burn-off length of the specimen has been determined depending on the original length of the two parts before welding and the length of the welded parts. During this phase of welding melting formation occurs, which is named as the burn-off length. Finally, in the forging stage during upset pressure, the welding process is completed by applying a high compressive force and stopping the relative motion. Table 3 shows the friction welding parameters of both types of polymers used in this research, and the length of the specimen before and after testing, to indicate the average burn-off length. 
TABLE (3) : Rotary friction welding parameters with average burn-off length.

\begin{tabular}{|c|c|c|c|c|c|c|}
\hline $\begin{array}{c}\text { Test } \\
\text { Number }\end{array}$ & $\begin{array}{c}\text { Friction } \\
\text { speed rpm }\end{array}$ & $\begin{array}{c}\text { Friction } \\
\text { Time sec. }\end{array}$ & $\begin{array}{c}\text { Type of } \\
\text { polymer }\end{array}$ & $\begin{array}{c}\text { Length } \\
\text { before test } \\
\text { mm }\end{array}$ & $\begin{array}{c}\text { Length } \\
\text { after } \\
\text { test } \mathbf{m m}\end{array}$ & $\begin{array}{c}\text { Average } \\
\text { burn-off } \\
\text { length } \mathbf{m m}\end{array}$ \\
\hline 1 & 560 & 60 & ABS & 136.3 & 125.5 & 10.8 \\
\hline 2 & 600 & 75 & ABS & 135.2 & 124.1 & 11.1 \\
\hline 3 & 650 & 90 & ABS & 133.42 & 122 & 11.4 \\
\hline 4 & 650 & 90 & PE & 124.2 & 121.64 & 2.56 \\
\hline 5 & 650 & 63 & PE & 125.9 & 119 & 6.9 \\
\hline 6 & 560 & 105 & ABS + PE & 128.72 & 123.94 & 4.76 \\
\hline 7 & 1030 & 80 & PE & 124.94 & 121.08 & 3.86 \\
\hline 8 & 1030 & 60 & ABS & 128.12 & 123.14 & 4.98 \\
\hline 9 & 950 & 62 & PE & 123.0 & 116.4 & 7.5 \\
\hline 10 & 950 & 90 & ABS+PE & 129.7 & 125.12 & 4.58 \\
\hline 11 & 1030 & 74 & ABS+PE & 130.84 & 126.36 & 4.48 \\
\hline 12 & 1030 & 93 & ABS & 132.82 & 129.58 & 3.24 \\
\hline
\end{tabular}

Then the entire specimens were prepared to the tensile test according to ASTM standard size on the Universal Tensile Machine model-type LY-1066A. Last step of the procedure consists of the calculating the efficiency of the welded joints.

\section{RESULTS AND DISCUSSION}

In fact, rotary friction welding includes three stages. In the first stage which is named the heat-up stage, the two components are brought into contact and an axial compressive force is applied which they have relative motion against each other. A cause to the friction heat generation occurs at the faying surfaces, the temperature of the components raise at the rubbing interface and this process leads to a decrease in the flow stress of the material. Eventually, the melted material is unable to withstand the applied axial compressive force and plastically flows outwards to form the contact surface. The main variables in the rotary friction welding process are axial force, rotational speed, and welding time. Based on these variables the amount of energy input to the weld and the rate of heat generation at the interface can be determined. It is important to mention that the rate of heat generation is not constant across the interface between the two materials.

\section{Tensile test}

Table 4 shows the results of tensile testing of welded specimen with rotary friction welding of both polymers PE and ABS. The peak stress, peak load, elongation, and time before fracture are shown in the table also. Noted that the fracture happened in the welded location, because the welded interface between the two polymers is weak and four couples of specimen were failed. For thermoplastic there is a critical sliding speed for each type of polymer. This speed generate localized flash temperature at the interface, which can be reached and caused surface melting and thermal softening near the contact surfaces. This flash temperature is caused by adhesive friction at the instantaneous contact interface. Finding the relative rotational speed is the important rotary friction parameter and has the inherent limitation that it cannot be used for non-circular cross-section components. Experimentally, it has no significant influence on the quality of the welding connection even it varies in a wide range. Test number 8 and 12 were failed for ABS type of polymer, because of the speed of the rotary reached the critical speeds. Also the test number 6, 10 and 11 were failed which the rotary friction welding between $\mathrm{ABS}$ and $\mathrm{PE}$, this indicated that the ABS and PE cannot be welded together using rotary friction welding. 
TABLE (4) : Experimental tensile test results

\begin{tabular}{|c|c|c|c|c|c|c|c|}
\hline $\begin{array}{c}\text { Test } \\
\text { number }\end{array}$ & $\begin{array}{c}\text { Type of } \\
\text { polymer }\end{array}$ & $\begin{array}{c}\text { Friction } \\
\text { Speed } \\
\text { rpm }\end{array}$ & $\begin{array}{c}\text { Friction } \\
\text { time sec. }\end{array}$ & $\begin{array}{c}\text { Peak } \\
\text { stress } \\
\text { MPa }\end{array}$ & $\begin{array}{c}\text { Peak load } \\
\text { KN }\end{array}$ & $\begin{array}{c}\text { Joint } \\
\text { efficiency } \\
\%\end{array}$ & $\begin{array}{c}\text { Average } \\
\text { burn-off } \\
\text { length } \\
\text { mm }\end{array}$ \\
\hline 1 & ABS & 560 & 60 & 24.5 & 0.695 & 0,863 & 10.8 \\
\hline 2 & ABS & 600 & 75 & 20.5 & 0.55 & 0.723 & 11.1 \\
\hline 3 & ABS & 650 & 90 & 16.3 & 0.46 & 0,574 & 11.4 \\
\hline 4 & PE & 650 & 90 & 14.175 & 0.4 & 0,474 & 2.56 \\
\hline 5 & PE & 650 & 63 & 9.6 & 0.268 & 0,321 & 6.9 \\
\hline $6^{*}$ & ABS+PE & 560 & 105 & & & & 4.76 \\
\hline 7 & PE & 1030 & 80 & 17.5 & 0.49 & 0,585 & 3.86 \\
\hline $8^{*}$ & ABS & 1030 & 60 & & & & 4.98 \\
\hline 9 & PE & 950 & 62 & 1.9 & 0.096 & 0,063 & 7.5 \\
\hline $10^{*}$ & ABS+PE & 950 & 90 & & & & 4.58 \\
\hline $11^{*}$ & ABS+PE & 1030 & 74 & & & & 4.48 \\
\hline $12^{*}$ & ABS & 1030 & 93 & & & & 3.24 \\
\hline
\end{tabular}

* Failed test

Fig. 2 shows the relationship between friction time and peak stress for PE and ABS polymer. For PE with increasing the friction time the peak stress will increase until 80 second then the peak stress will step down, where for ABS shows decreasing behavior because ABS polymer is hard and tough. And these types of polymers $\mathrm{ABS}$ and $\mathrm{PE}$ are viscoelastic and their

properties are time dependent. That is, the defects created in the interface of the welded joints reduced the tensile strength of joints. Whenever. Whenever the weld speed is higher the irradiation time is lower and this gives low heat input to the zone welding, resulting in weak weld.

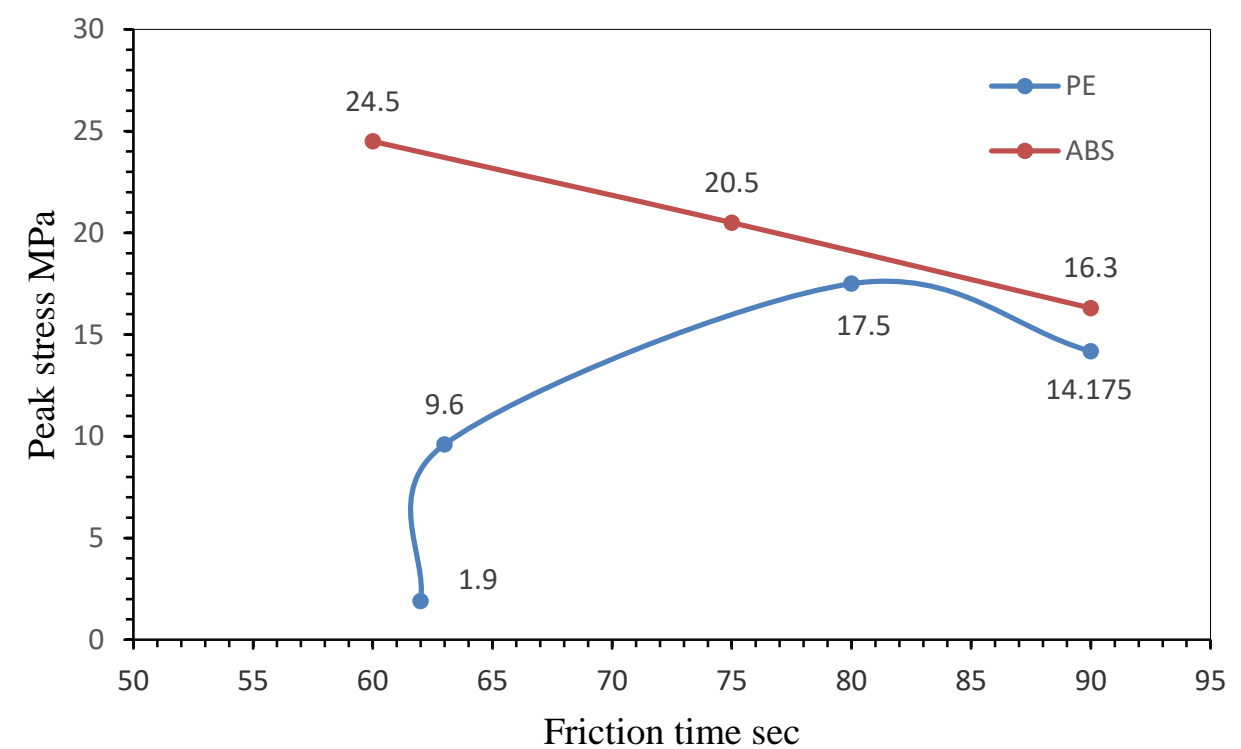

Fig (2) : Relationship between friction time and peak stress for both ABS and PE

In Fig. 3 the effect of friction speed on peak stress are explained. For PE polymer at low speed with increasing the friction time the peak stress significantly increase and reaches twice value. Also with increasing the friction speed the peak stress increases gradually. While for ABS polymer with increasing friction speed the peak stress decreases and after the friction speed exceed the range of $650 \mathrm{rpm}$ the tests are failed because there are 
certain optimum speeds for each application and individual material combination. Another note is, across the welding interface between the two different materials at the high rotational speeds, there is a possibility of creating a non-uniform heat generation which led to the spread of the irregular mixed compound in the interfacial region during the rotary fiction welding process and these phenomena may be responsible for the brittle failure of the welded joints. Trying to change the rotational speed during rotary friction welding to improve mechanical properties is nonessential.

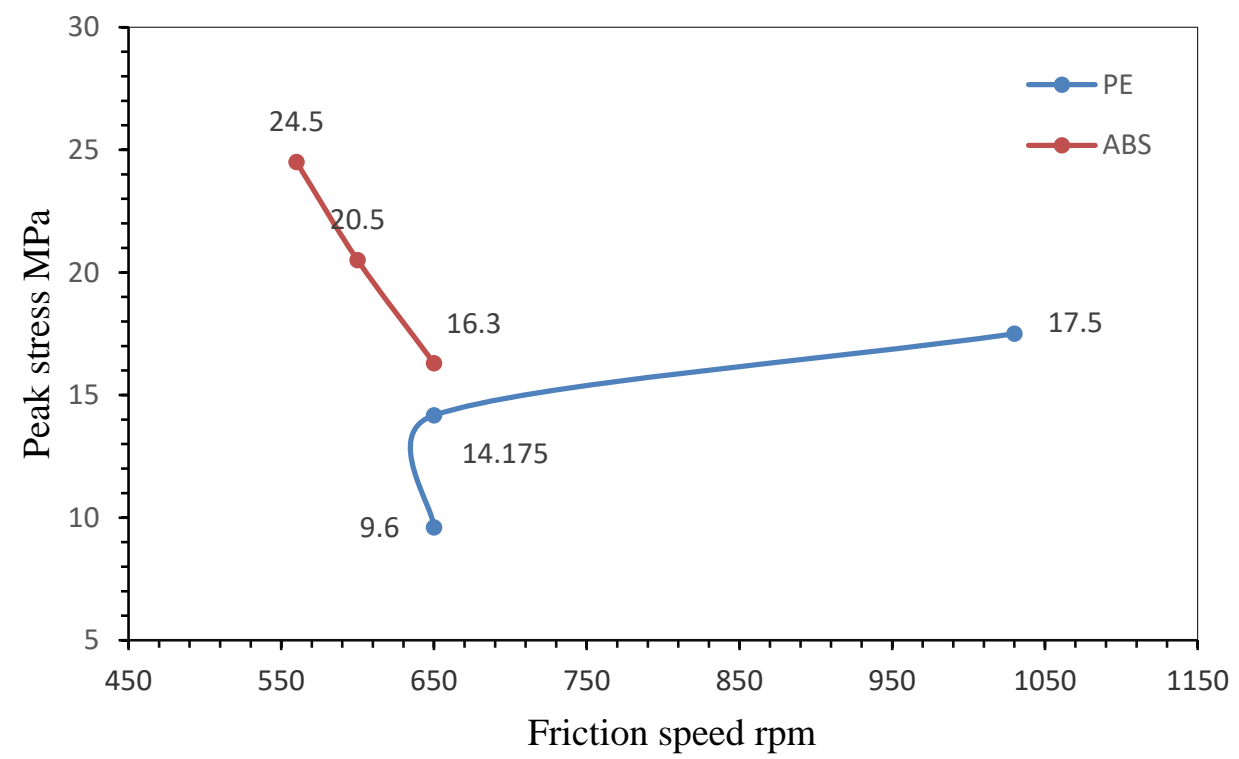

Fig (3) : Relationship between friction speed and peak stress for both ABS and PE

\subsection{Average burn-off length:}

The relationship between friction variables and the burn-off length for ABS and PE polymer showed in Fig. 4 and 5 . We noticed that in Fig. 4 by increasing the friction time the average burn-off length decreases, while for ABS and ABS with PE increased slightly. Where in Fig. 5 the effect of friction speed has inverse action compared with friction time. But for ABS with PE specimen there is no significant effect of friction speed and friction time on the average burn-off length. During the heat-up stage, the two polymers, which have relative motion against each other, are brought into contact by applying an axial compressive force. Heat generated by rotary friction at the faying surfaces raises the temperature of the polymer materials at the rubbing interface and this leads to a decrease in the flow stress of the welded polymer material.

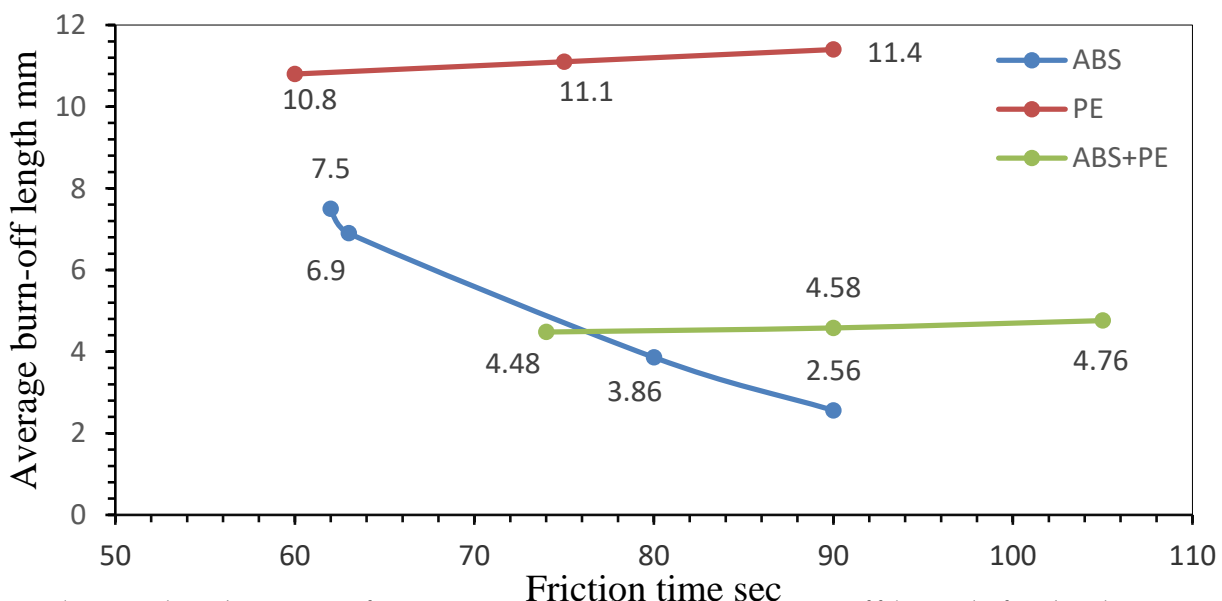

Fig (4) : Relationship between friction time and average burn-off length for both ABS and PE 


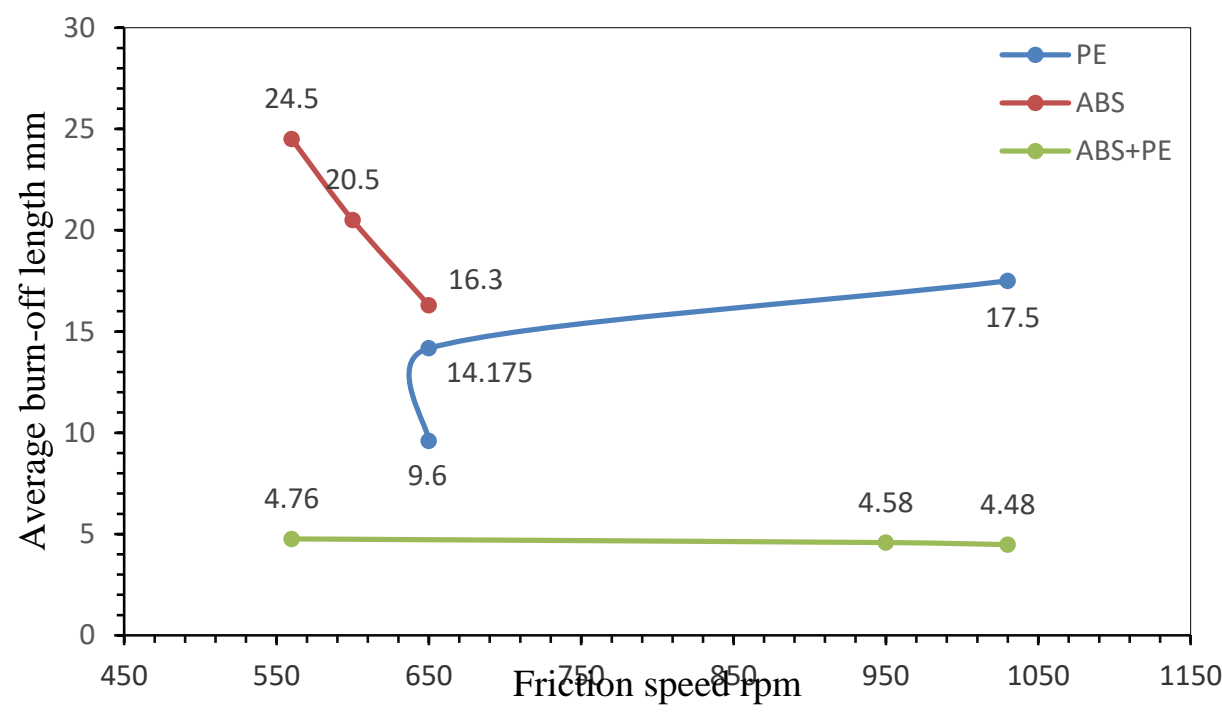

Fig (5) : Relationship between friction speed and average burn-off length for both ABS and PE

\subsection{Welding joint efficiency:}

In Fig. 6 and 7 we explained the relationship between efficiency of the welded joints and variables of the rotary friction welding. We can define the joint efficiency as the ratio of joint tensile strength of the welded material to the ultimate tensile strength of the base materials for both ABS and PE. For PE polymer the welding joint efficiency will increase with increasing both variables of friction (time and speed). Noting that the ABS polymer behaves invers as PE polymer. The optimum efficiency value for PE polymer is 58.5\% which is obtained at the speed of $1030 \mathrm{rpm}$ and at friction time 80 second, and for ABS the best efficiency value is $86.3 \%$ with speed of $550 \mathrm{rpm}$ and rotary friction time 60 second.

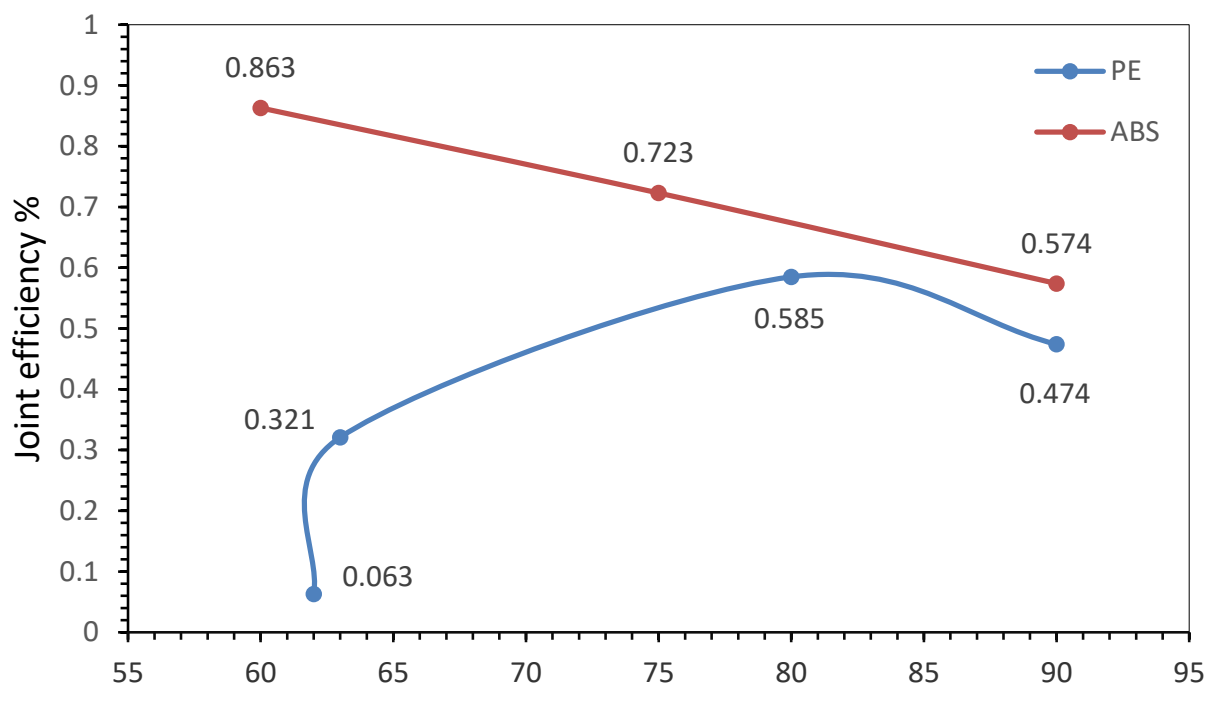

Friction time sec

Fig (6) : Relationship between friction time and joint efficiency \% for both ABS and PE 


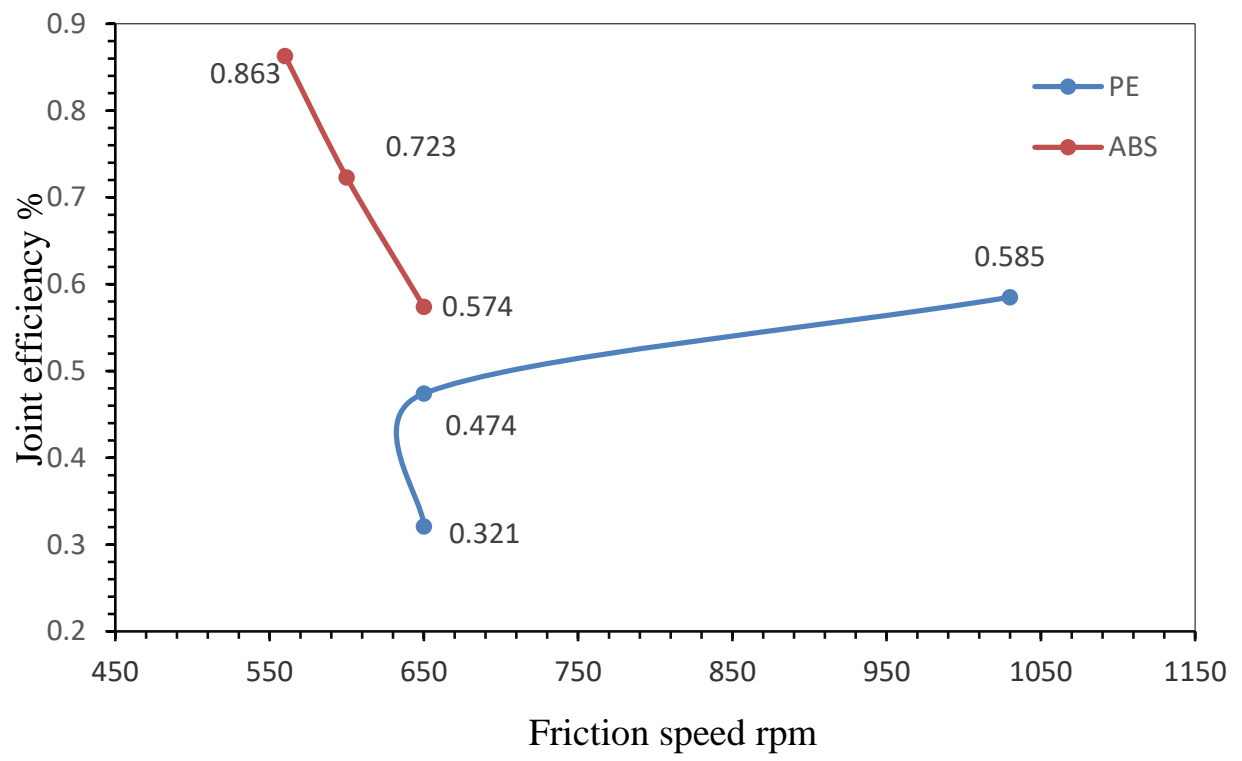

Fig (7) : Relationship between friction speed and joint efficiency \% for both ABS and PE

\subsection{Macrostructure observing of fracture location}

Fig. 8 shows the examples of the appearances of the weld joints interfaces after rotary friction welding of PE and ABS, noting that the different ranges of concentric rubbing marks of failed points were observed at those regions of the weld interface for both materials. Using the samples at different rotational speeds as an example, the images of fracture surface of the joints are shown. All samples showed a rough surface which included the different rubbing marks of varying shapes.
And the different colors of the fractured area interpret the ranges of week and strong points of the rotary friction welding between the two materials. The weld faying surfaces of the materials PE and ABS are rubbed against each other from their contact areas, and the concentric rubbing phenomena can be duplicated from the circumferences portion toward the central area of the weld joints interfaces. Because that the rate of heat generation is not uniform over the interface.

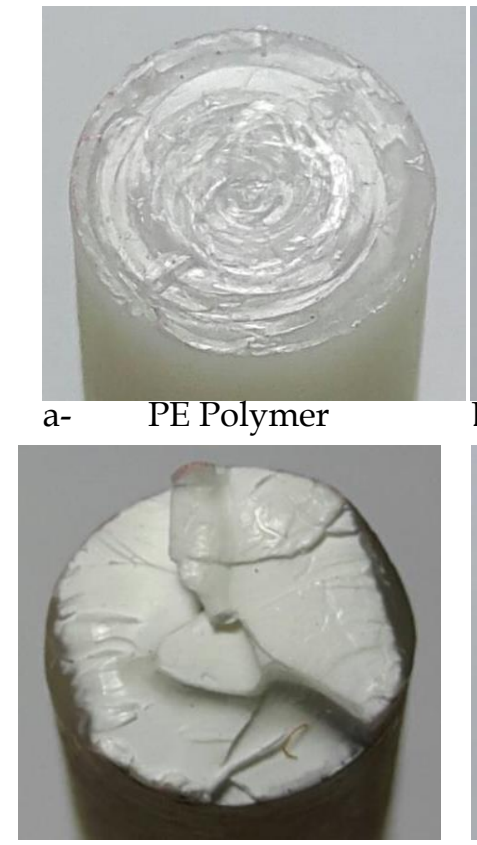

b- $\quad$ ABS Polymer

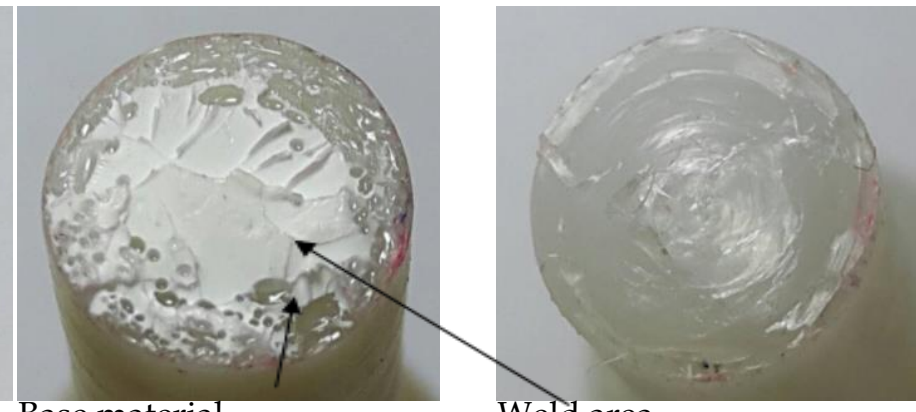

Base material Weld area

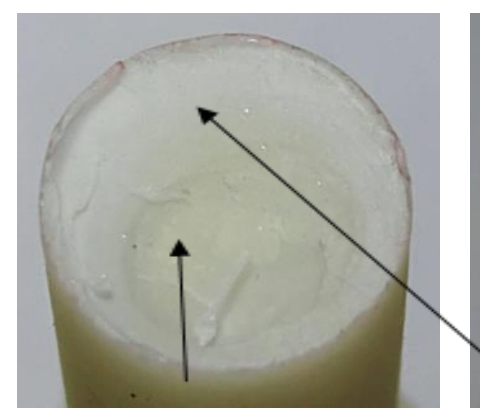

Base material

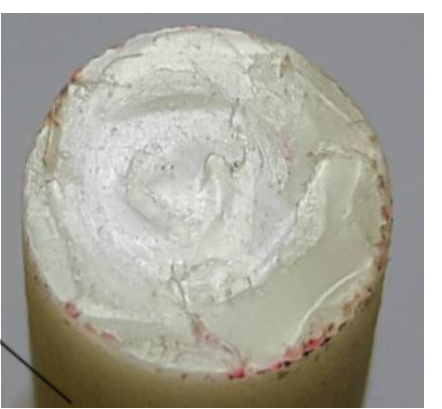

Weld area

Fig (8) : Macroscopic illustration of the different fracture locations 


\section{CONCLUSION}

- Based on the data of this research it is not possible to weld $\mathrm{PE}$ and ABS polymer together using rotary friction welding.

- The best values of the tensile strength can be obtained at low speed with low friction time in the studied range for ABS polymer.

- For ABS with PE specimen there are no significant effects of friction speed and friction time on the average burn-off length.

- The best values of the tensile strength can be obtained at high speed with high friction time in the studied range for PE polymer.

- The optimum efficiency value for PE polymer is 58.5\% which is obtained at the speed of $1030 \mathrm{rpm}$ and at friction time 80 second, and for ABS the best efficiency value is $86.3 \%$ with speed of $550 \mathrm{rpm}$ and rotary friction time 60 second.

\section{ACKNOWLEDGMENTS}

Thanks to engineer Dler Ahmed, Bayan Abdul Aziz and Sazan Majid for their efforts helping us in the practical part.

\section{REFERENCES}

1. Abdelbary, A. (2015). Wear of polymers and composites: Woodhead Publishing.

2. Aoki, K., \& Koezawa, T. (2017). Characteristics of friction welding within a short time for aluminum alloy deformed by ECAE process. Procedia Engineering, 207, 597-602.

3. Bühr, C., Ahmad, B., Colegrove, P. A., McAndrew, A. R., Guo, H., \& Zhang, X. (2018). Prediction of residual stress within linear friction welds using a computationally efficient modelling approach. Materials \& Design, 139, 222-233.

4. Gao, J., Li, C., Shilpakar, U., \& Shen, Y. (2016). Microstructure and tensile properties of dissimilar submerged friction stir welds between HDPE and ABS sheets. The International Journal of Advanced Manufacturing Technology, 87(1-4), 919-927.

5. Handa, A., \& Chawla, V. (2014). An investigation on the effect of axial pressures on the mechanical properties of friction welded dissimilar steels. Advances in Mechanical Engineering, 6, 639378.

6. Hynes, N. R. J., Prabhu, M. V., \& Nagaraj, P. (2017). Joining of hybrid AA6063-6SiC p-3Gr p composite and AISI 1030 steel by friction welding. Defence Technology.

7. Jung, D.-J., Cheon, J., \& Na, S.-J. (2016). Effect of surface pre-oxidation on laser assisted joining of acrylonitrile butadiene styrene (ABS) and zinc-coated steel. Materials \& Design, 99, 1-9.

8. Kimura, M., Kasuya, K., Kusaka, M., Kaizu, K., \&
Fuji, A. (2009). Effect of friction welding condition on joining phenomena and joint strength of friction welded joint between brass and low carbon steel. Science and Technology of Welding and Joining, 14(5), 404-412.

9. Kimura, M., Saitoh, Y., Kusaka, M., Kaizu, K., \& Fuji, A. (2011). Effect of friction pressure on joining phenomena of friction welds between pure titanium and pure copper. Science and Technology of Welding and Joining, 16(5), 392-398.

10. Kumar, R., Singh, R., Ahuja, I., Amendola, A., \& Penna, R. (2018). Friction welding for the manufacturing of PA6 and ABS structures reinforced with Fe particles. Composites Part B: Engineering, 132, 244-257.

11. Lin, C., Wu, L.-C., \& Chou, Y.-C. (2003). Effect of solvent and cosolvent on friction welding properties between part of PMMA with PVC. Journal of materials science, 38(12), 2563-2570.

12. Liu, F., Liao, J., \& Nakata, K. (2014). Joining of metal to plastic using friction lap welding. Materials \& Design (1980-2015), 54, 236-244.

13. Parsa, M., Davari, H., Hadian, A., \& Ahmadabadi, M. N. (2007). Thermo-Mechanical Calculations of Hybrid Rotary Friction Welding at Equal Diameter Copper Bars and Effects of Essential Parameters on Dependent Special Variables. Paper presented at the AIP Conference Proceedings.

14. Singh, R., Kumar, R., Feo, L., \& Fraternali, F. (2016). Friction welding of dissimilar plastic/polymer materials with metal powder reinforcement for engineering applications. Composites Part B: Engineering, 101, 77-86.

15. Uday, M., \& Ahmad-Fauzi, M. (2014). Joint properties of friction welded 6061 aluminum alloy/YSZ-alumina composite at low rotational speed. Materials \& Design, 59, 76-83.

16. Uday, M., Fauzi, M. A., Zuhailawati, H., \& Ismail, A. (2011). Effect of welding speed on mechanical strength of friction welded joint of YSZ-alumina composite and 6061 aluminum alloy. Materials Science and Engineering: A, 528(13), 4753-4760.

17. Zafar, A., Awang, M., \& Khan, S. R. (2017). Friction Stir Welding of Polymers: An Overview. Paper presented at the 2nd International Conference on Mechanical, Manufacturing and Process Plant Engineering.

${ }^{1}$ Corresponding author: Dr. PhD. Younis Khalid Khdir, Tel.: +964 7504790685 E-mail : younis.khdir@epu.edu. 